\title{
Resistance profile of Staphylococcus aureus strains isolated from patients treated in a tertiary care hospital in Romania
}

\author{
Oana Săndulescu ${ }^{1,2^{*}}$, Andrei Grigoraş ${ }^{1}$, Anca Streinu-Cercel ${ }^{1,2}$, loana Berciu ${ }^{1,2}$, Alina Cristina Neguț ${ }^{1,2}$, \\ Adrian Streinu-Cercel ${ }^{1,2}$ \\ From The 10th Edition of the Scientific Days of the National Institute for Infectious Diseases "Prof Dr Matei \\ Bals" \\ Bucharest, Romania. 15-17 October 2014
}

\section{Background}

The prevalence of colonization with Staphylococcus aureus has been shown to increase worldwide [1,2], along with the rate of antibiotic use in medicine as well as the livestock industry. Therefore, our microbiota may be exposed to selective pressure and may develop resistance to current drugs [3].

\section{Methods}

We have performed a study to assess the antimicrobial susceptibility profile of $S$. aureus strains isolated from clinically apparent infections treated in the National Institute for Infectious Diseases "Prof. Dr. Matei Balş". Bacterial identification and antimicrobial sensitivity testing were performed on MALDI-TOF or VITEK (bioMérieux, Paris, France).

\section{Results}

We examined 149 strains of S. aureus, $44.9 \%$ from cutaneous wound infections, $31.2 \%$ from blood cultures, $8.4 \%$ from sputum samples and $15.3 \%$ from other infection sites. Of the total number of strains identified, $55.7 \%$ were resistant to methicillin, $35.1 \%$ were resistant to clindamycin (D-test results are presented separately), 30.9\% were resistant to levofloxacin, $18.7 \%$ were resistant to rifampin and smaller percentages were identified for resistance to other drugs. Surprisingly, resistance was also identified to drugs that are not used in clinical practice in Romania, such as daptomycin (6.8\%) or fusidic acid (4.8\%), suggesting a possible international circulation of $S$. aureus strains,

\footnotetext{
* Correspondence: oanasandulescu1@gmail.com

${ }^{1}$ Carol Davila University of Medicine and Pharmacy, Bucharest, Romania
}

Full list of author information is available at the end of the article probably through means of nasal or axillary carriage. We excluded a mechanism of daptomycin non-susceptibility through thickened bacterial cell walls in strains of vancomycin-intermediate $S$. aureus, as all strains were susceptible to vancomycin.

\section{Conclusion}

Antimicrobial resistance remains a major issue in clinical practice, but studies describing the local antimicrobial susceptibility patterns of important pathogens can aid in guiding first-line antibiotherapy.

\section{Acknowledgements \\ 1) This paper is partially supported by the Sectoral Operational Programme Human Resources Development (SOP HRD), financed from the European Social Fund and by the Romanian Government under the contract numbers POSDRU/159/1.5/S/137390. \\ 2) This paper is partially supported by the Carol Davila University of Medicine and Pharmacy, Young Researchers Projects Grant Competition, contract number 28.336/04.11.2013.}

\section{Authors' details}

'Carol Davila University of Medicine and Pharmacy, Bucharest, Romania. ${ }^{2}$ National Institute for Infectious Diseases "Prof. Dr. Matei Balş", Bucharest, Romania.

\section{Published: 15 October 2014}

\section{References}

1. Preoțescu LL, Streinu-Cercel O: Prevalence of nasal carriage of $S$ aureus in children. GERMS 2013, 3:49-51.

2. Mimica MJ, Bádue-Pereira MF: Staphylococcus aureus colonization in Brazilian children. GERMS 2014, 4:22.

3. de Lastours V, Chau F, Roy C, Larroque B, Fantin B: Emergence of quinolone resistance in the microbiota of hospitalized patients treated or not with a fluoroquinolone. J Antimicrob Chemother 2014, pii:dku283. 
doi:10.1186/1471-2334-14-S7-P59

Cite this article as: Săndulescu et al:: Resistance profile of Staphylococcus aureus strains isolated from patients treated in a tertiary care hospital in Romania. BMC Infectious Diseases 2014 14(Suppl 7):P59.

Submit your next manuscript to BioMed Central and take full advantage of:

- Convenient online submission

- Thorough peer review

- No space constraints or color figure charges

- Immediate publication on acceptance

- Inclusion in PubMed, CAS, Scopus and Google Scholar

- Research which is freely available for redistribution

Submit your manuscript at www.biomedcentral.com/submit

() BioMed Central 